Check for updates

Cite this: RSC Adv., 2018, 8, 10883

\title{
Extremely flat metal films implemented by surface roughness transfer for flexible electronics $\uparrow$
}

\author{
Kisoo Kim, (D) $\$$ Sungjoo Kim, (D) $\$$ Gwan Ho Jung, (D) Ilhwan Lee, (D) Sungjun Kim, \\ Juyoung Ham, (D) Wan Jae Dong, (D) Kihyon Hong (D) $\S$ and Jong-Lam Lee (D)*
}

\begin{abstract}
We present an innovative approach to fabricate an extremely flat (EF) metal film which was done by depositing metal on an extremely flat mother substrate, then detaching the metal from the substrate. The detached flexible metal films had a roughness that was within $2 \%$ of the roughness of the mother substrate, so EFs with $R_{\mathrm{a}}<1 \mathrm{~nm}$ could be fabricated using the surface roughness transfer method. With quantitative analysis using in situ synchrotron XPS, it was concluded that the chemical reaction of oxygen atoms with the metal film played a critical role in designing a peel-off system to get extremely flat metal films from the mother substrate. The OLED was successfully implemented on the metal film. The OLED's luminance could be increased from 15142 to $17100 \mathrm{~cd} \mathrm{~m}^{-2}$ at $25 \mathrm{~mA} \mathrm{~m} \mathrm{~m}^{-2}$ by replacing the glass substrate with an EF copper $(\mathrm{Cu})$ substrate, due to the enhanced heat dissipation during the operation. This novel method can be very useful for mass production of large scale, low-cost and high quality metal films using roll-to-roll process.
\end{abstract}

Received 11th January 2018

Accepted 7th March 2018

DOI: $10.1039 / \mathrm{c} 8 \mathrm{ra00298c}$

rsc.li/rsc-advances used to suppress the defects, but the thermal budget of polyimide films is low to obtain dielectric films with high quality. ${ }^{19}$ The high energy of the laser would also damage the surface of the metal layer. ${ }^{18}$ As an alternative approach, steel substrates have been studied, but they have rough surface, so additional planarization processes are required. ${ }^{21-23}$ A polishing process of the conventional steel substrate and a polymer coating process on the substrate do not satisfy the requirements for low price, low defect density, and low tack time. ${ }^{24,25}$ The steel substrate also has still high surface roughness $\left(R_{\mathrm{a}}>2 \mathrm{~nm}\right)$ after the planarization. ${ }^{26,27}$ Use of a metal substrate is ideal in flexible electronics because it has excellent mechanical strength, and heat resistance greater than that of a glass substrate. However, most metal films have very rough surface to be used in the devices. So, a novel, low-cost, high-throughput, flexible and extremely flat metal films is needed.

Here, we present an innovative approach to fabricate an extremely flat (EF) metal films by depositing a metal film on an extremely flat mother substrate, then detaching the metal film from the substrate. The detached films had the roughness that was within $2 \%$ of the roughness of the mother substrate, so EFs with average roughness $R_{\mathrm{a}}<1 \mathrm{~nm}$ could be fabricated without any polishing or planarization process. We demonstrated EF Ag film ( 8 inch, $R_{\mathrm{a}}=0.57 \mathrm{~nm}$, maximum roughness amplitude $R_{\mathrm{t}}=$ $5.75 \mathrm{~nm})$ and Cu film $\left(20 \mathrm{~cm} \times 20 \mathrm{~cm}, R_{\mathrm{a}}=2.42 \mathrm{~nm}, R_{\mathrm{t}}=30.04\right.$ $\mathrm{nm})$. Consequently, excellent flatness allows fabrication of various electronic devices on the detached metal surface. The optical and electrical performances of flexible organic lightemitting diodes (OLEDs) and organic photovoltaics (OPVs)
Division of Advanced Materials Science, Department of Materials Science and Engineering, Pohang University of Science and Technology (POSTECH), Pohang, 790-784, Korea. E-mail: jllee@postech.ac.kr

$\dagger$ Electronic supplementary information (ESI) available. See DOI: 10.1039/c8ra00298c

\$ These two individuals contributed equally to this work.

$\S$ Present address: Department of Materials Science and Engineering, Chungnam National University, Daejeon, 34134 (Korea) 
using EF metal films were comparable to those on rigid glass substrate.

\section{Experimental section}

\section{Preparation of EF metal film}

Glass, indium-tin oxide (ITO) and silicon (single-side polished) were used as a mother substrate for fabricating EF metal film. The mother substrate was cleaned sequentially with acetone, isopropyl alcohol, and deionized water, on which metal films were deposited by various techniques such as a thermal evaporation, electron-beam evaporation, or electroplating. When the evaporation method was used, $\mathrm{Ag}$ films were deposited to $30 \mu \mathrm{m}$ thickness at a rate of $1.0 \mathrm{~nm} \mathrm{~s}^{-1}$. The growth chamber pressure was maintained at $\sim 10^{-8}$ Torr during the deposition, and the substrate was held at room temperature. Then, adhesive support film was attached to the Ag film for the effective pee-off process in the large-area film. The support film with the 8 inch $\mathrm{Ag}$ film was successfully detached from the Si substrate. A large compressive stress could be built at the interface of the $\mathrm{Ag}$ film with the $\mathrm{Si}$ substrate due to their lattice parameter change $(4.08 \AA$ for $\mathrm{Ag}$ and $5.43 \AA$ for $\mathrm{Si}$ ). This led to easily peel-off of the $\mathrm{Ag}$ film from the Si substrate. Metal films ( $\mathrm{Cu}, \mathrm{Ni}$ or invar) could be grown on the mother substrates by evaporating to a thickness of several tens of nanometers. Subsequently, same kinds of metal films were electroplating to thicken the metal films to several tens of micrometers. To electroplate metal films on the mother substrate, the cathode (metal layers on mother substrate) and anode (bulk plating material stick) were electrically connected using a Keithley 2400 digital source meter to ensure constant current density. The temperature of the electroplating solution was maintained to be $60^{\circ} \mathrm{C}$. All films could be easily peeled off from the mother substrate.

\section{Fabrication of top-emission OLEDs}

Glass $\left(R_{\mathrm{a}}=1.3 \mathrm{~nm}\right)$ was used as the reference substrate. EF $\mathrm{Cu}\left(R_{\mathrm{a}}=1.4 \mathrm{~nm}\right)$ and rolled STS $430\left(R_{\mathrm{a}}=53.0 \mathrm{~nm}\right)$ substrate was used to test effects of surface roughness and topemission OLEDs were fabricated on the substrates. The substrates were cleaned sequentially with acetone, iso-propyl alcohol and deionized water and then dried with a highpurity $\mathrm{N}_{2}$ gas. The substrates were transferred to a PECVD, then a $100 \mathrm{~nm}$-thick $\mathrm{SiO}_{2}$ insulation layer was deposited on the substrate. Afterward, the insulated samples were transferred to a thermal evaporator. A metal (Ag $100 \mathrm{~nm}) /$ dielectric $\left(\mathrm{WO}_{3} 3 \mathrm{~nm}\right)$ structure was used for reflective anode elec-

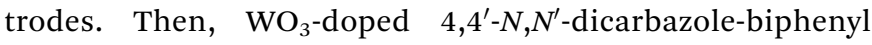
(CBP) as a $28 \mathrm{~nm}$ hole injection layer (HIL), intrinsic CBP as a $5 \mathrm{~nm}$ hole transport layer (HTL), Tris[2-phenylpyridinatoC2, N]iridium(III) (Irppy ${ }_{3}$ ) doped CBP as a $20 \mathrm{~nm}$ emissive layer (EML), 1,3,5-tris(1-phenyl-1 $H$-benzimidazol-2-yl) benzene (TPBi) as a $35 \mathrm{~nm}$ electron transporting layer (ETL), LiF as a $1 \mathrm{~nm}$ electron injection layer (EIL), Al (2 nm) and $\mathrm{Ag}(18 \mathrm{~nm})$ as transparent cathodes, and $\mathrm{WO}_{3}(30 \mathrm{~nm})$ as admittance matching layer were deposited in sequence.
During deposition, the base pressure of the chamber was maintained as low as $10^{-6}$ Torr. The active area of the device was $30 \mathrm{~mm} \times 30 \mathrm{~mm}$.

\section{Characterization}

X-ray photoelectron spectroscopy was carried out using synchrotron X-ray in 4D beam line in Pohang Accelerator Laboratory. The average surface roughness (at 5 randomlyselected points) of flexible EF metal films and mother substrates were measured by using a 3D-profiler (Wyko Veeco, NT1100) with a scan range of $1.2 \mathrm{~mm} \times 0.9 \mathrm{~mm}$ and an AFM (Veeco-Digital instruments MMAFMLN-AM) in tapping mode using Sb-doped Si cantilevers. The current density-voltage $(J-V)$ characteristics and luminance $(L)$ of the OLEDs were measured with a Keithley 2400 source meter in a nitrogen ambient atmosphere. The $J-V$ curves of OPVs were measured under air ambient with glass encapsulation using a Keithley 2400 source measurement unit. The photocurrent was measured under AM1.5 $100 \mathrm{~mW} \mathrm{~cm}^{-2}$ illumination from an Oriel $150 \mathrm{~W}$ solar simulator. The light intensity was determined using a monosilicon detector calibrated by the National Renewable Energy Laboratory (NREL).

\section{Results and discussion}

In order to fabricate EF metal films using a surface roughness transfer method, a flexible metal film was formed on mother substrate using various techniques such as thermal evaporation, electron-beam evaporation, or electroplating (Fig. 1a). In this study, we used Si wafers (8 inch), glass, ITO-coated glass $(20 \mathrm{~cm} \times 20 \mathrm{~cm})$, and stainless steel (STS) sheets as the mother substrates. The flexible metal films with $30-100 \mu \mathrm{m}$-thick Ag, invar, $\mathrm{Cu}$, or $\mathrm{Ni}$ were separately detached from the mother substrate (Fig. 1b). This allows the roughness of mother substrate to transfer to the detached surface of the flexible metals film, so EF metal films could be made by using the extremely flat mother substrates (Fig. 1c). Finally, various kinds of electronic devices such as OLEDs and OPVs can be fabricated on top of the detached surface of the metal films (Fig. 1d). As an example, EF Ag film was obtained by depositing a $30 \mu \mathrm{m}$-thick $\mathrm{Ag}$ film on an 8-inch $\mathrm{Si}$ wafer, then peeled-off from the $\mathrm{Si}$ wafer (Fig. 1e). The Ag film could be transferred to support film without any cracks (Fig. 1f) because of intrinsic flexibility of the Ag. The detached side of Ag film had $0.57 \mathrm{~nm} \leq R_{\mathrm{a}} \leq 0.78 \mathrm{~nm}$ and $5.75 \mathrm{~nm} \leq R_{\mathrm{t}} \leq 9.85 \mathrm{~nm}$. X-ray photo-emission spectroscopy revealed that there is no transfer of atomic components by the peel-off process (Fig. S1 $\dagger$ ). In addition to $\mathrm{Ag}$ film, it has been confirmed that a large-area $\mathrm{Cu}$ film can be produced by using this method (Fig. S2 $\dagger$ ).

Chemical composition of surfaces of peeled-off film was in situ characterized in ultra-high vacuum using synchrotron radiation photoemission spectroscopy (SRPES). The Ag film coated on $120 \mathrm{~nm}$-thick ITO-coated glass was peeled off (Fig. 2a) in the vacuum chamber, and $\mathrm{Ag} 3 \mathrm{~d}$ and In $3 \mathrm{~d}$ SRPES spectra were collected from both surfaces of peeled-off Ag film (Fig. 2b) and ITO substrate (Fig. 2c). The peak intensity $\left(3 \mathrm{~d}_{5 / 2}\right)$ at $368.8 \mathrm{eV}$ 
a

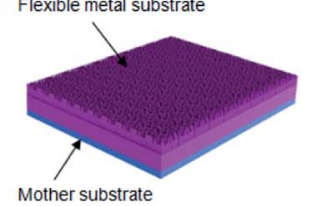

C Flat flexible metal substrate
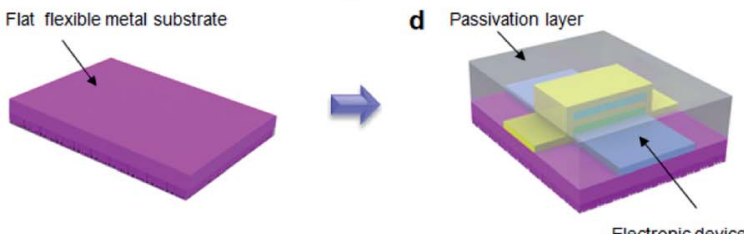

Electronic devices

e

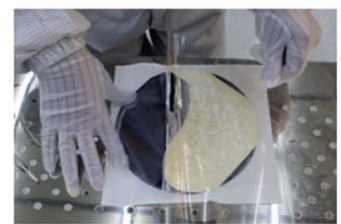

Passivation layer

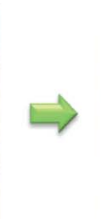

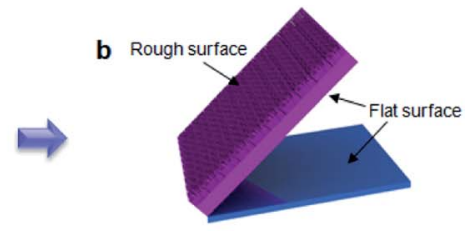
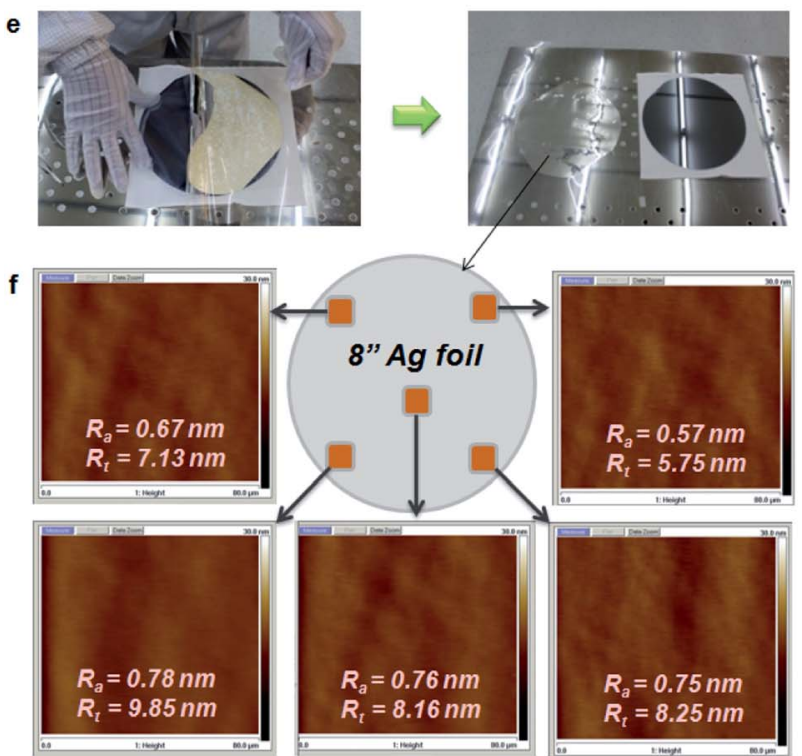

Fig. 1 Generic process flow for extremely flat metal film using surface roughness transfer method. (a) Flexible metal film was formed on the mother substrate. (b) The flexible metal film was detached from the mother substrate. (c) The roughness of detached surface in the flexible metal film was transferred from the mother substrate. (d) Electronic devices were fabricated on top of detached surface in the metal film. (e) Photo images of peel-off process using Ag/Si wafer, corresponding (b) and (c) figures. (f) Surface roughness of an 8 inch Ag foil measured by AFM.

(Ag-Ag metallic bond) was stronger than the peak at $368.3 \mathrm{eV}$ (Ag-O covalent bond), meaning that oxygen atoms on ITO have hardly bonded with $\mathrm{Ag} .{ }^{28,29}$ There was no peak corresponding to In on the surface of Ag film. Similarly, no peak attributable to Ag was found on the surface of ITO substrate. This provides an evidence that there was no chemical reactions between $\mathrm{Ag}$ and the ITO interface. This lack of chemical reaction could be explained by the Gibbs free energy change to form an oxide, which is more negative for $\operatorname{In}_{2} \mathrm{O}_{3}\left(-831 \mathrm{~kJ} \mathrm{~mol}^{-1}\right)$ and $\mathrm{SnO}_{2}$ $\left(-520 \mathrm{~kJ} \mathrm{~mol}^{-1}\right)$ than for AgO $\left(-11 \mathrm{~kJ} \mathrm{~mol}^{-1}\right){ }^{30}$

To compare the peel-off mechanism between the reacting metal and non-reacting metal, the Ti layer on the ITO glass was peeled off (Fig. 3a), and the change in atomic composition with sputtering depth was quantified in the peeled-off $\mathrm{Ti}$ layer (Fig. 3b). At the Ti surface (3 $\AA$ sputtered), the peak $\left(2 \mathrm{p}_{3 / 2}\right)$
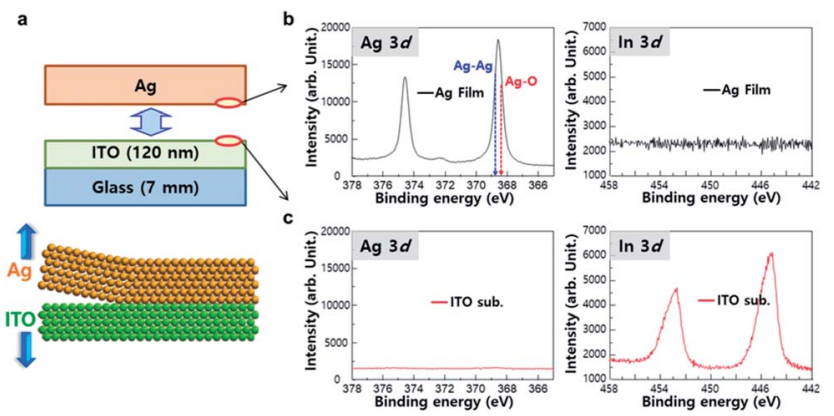

Fig. 2 Interfacial reactions between Ag layer and ITO substrate on peel-off process. (a) Schematic drawing of Ag film peeled-off from ITO substrate. (b) Ag 3d and In 3d SRPES spectra of the surface of peeledoff Ag film. (c) Ag 3d and In 3d SRPES spectra at the surface of peeledoff ITO layer.

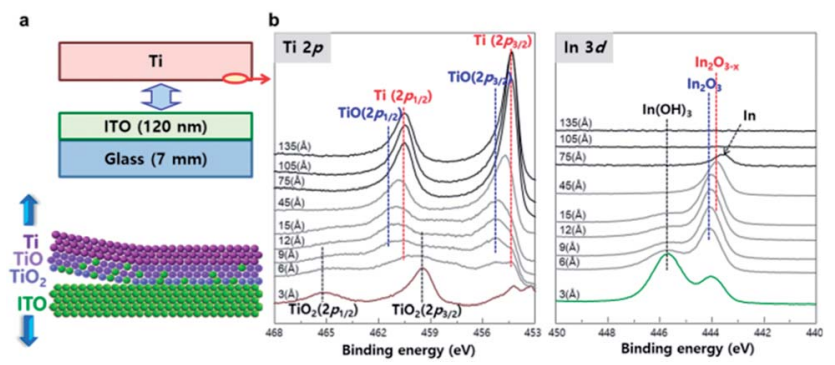

Fig. 3 Interfacial reactions of Ti/ITO interface and depth profiling of Ti layer. (a) Schematic representation of peel-off reaction at Ti/ITO interface. (b) Ti $2 p$ (left) and In 3d (right) spectra of lower side of peeled-off Ti layer as a function of sputtering depth.

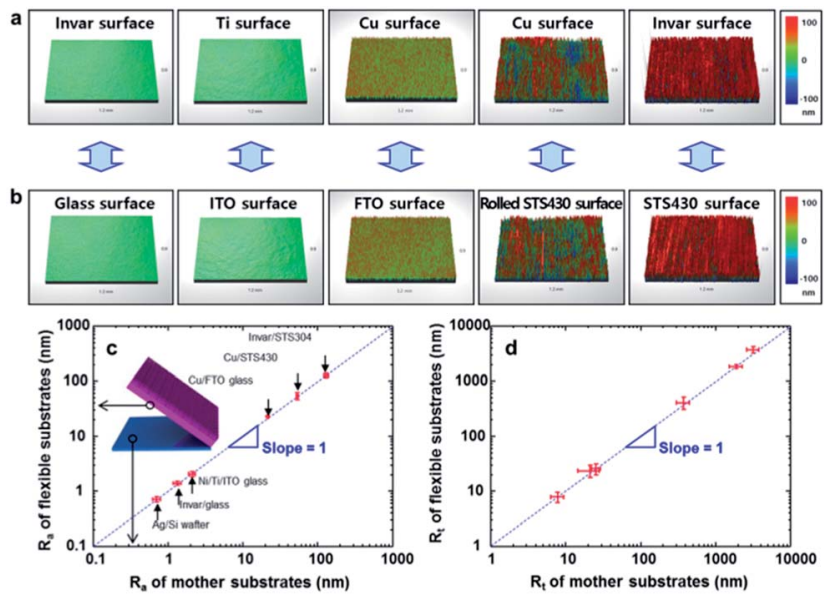

Fig. 4 Surface roughness transfer from mother substrates to flexible metal films. (a) Peeled-off metal surfaces, and (b) peeled-off mother substrates for invar/glass, Ti/ITO, Cu/FTO, Cu/Rolled STS430 and invar/STS430 interfaces, (c) average roughness $\left(R_{\mathrm{a}}\right)$ of flexible metal films versus $R_{\mathrm{a}}$ of mother substrates and (d) maximum roughness amplitude $\left(R_{\mathrm{t}}\right)$ of flexible metal films versus $R_{\mathrm{t}}$ of mother substrates.

centered at $459.5 \mathrm{eV}$ corresponds to the $\mathrm{TiO}_{2}$ fully-oxidized state that has a $\mathrm{d}^{0}$ configuration in the ground state. ${ }^{31,32}$ The peak at $455.3 \mathrm{eV}$ could be assigned to the covalent TiO state. ${ }^{33}$ These 
Table 1 Average ( $n=5$ ) surface roughness of peeled-off metal film (top 3 values in column) and mother substrate (bottom 3 values in column)

\begin{tabular}{|c|c|c|c|c|c|c|}
\hline$R_{\mathrm{a}}(\mathrm{nm})$ & 0.7 & 1.4 & 2.1 & 22.9 & 54.1 & 127.2 \\
\hline$R_{\mathrm{q}}(\mathrm{nm})$ & 0.9 & 1.8 & 2.6 & 28.8 & 71.1 & 180.4 \\
\hline Mother substrate & $\mathrm{Si}_{(\mathrm{AFM})}$ & Glass & ITO & FTO & Rolled STS430 & STS430 \\
\hline$R_{\mathrm{t}}(\mathrm{nm})$ & 7.8 & 21.2 & 25.3 & 374.6 & 1895.7 & 3180.0 \\
\hline
\end{tabular}

peaks are related to the atomic oxygen of oxide-like structures characterized by covalent Ti-O bonding. As the depth of the sputtered Ti layer reached $45 \AA$, a sharp metallic peak appeared. The intensity of the metallic Ti peak increased with sputtering depth. These results suggest that the surface of the Ti layer had been oxidized by the ITO layer. The depth profile of the In 3d region demonstrates that metallic $\mathrm{In}^{0}$ compounds from the ITO layer were transferred to the peeled-off Ti layer. The chemical composition of In-O bonds changed with sputtering depth; i.e., from highly-oxidized $\operatorname{In}(\mathrm{OH})_{3}$ to $\operatorname{In}_{2} \mathrm{O}_{3}$ to $\operatorname{In}_{2} \mathrm{O}_{3-x}$ to metallic In,$^{33}$ then the signal of metallic In disappeared at sputtering depth $\sim 100 \AA$. The peeled ITO did not show signs of Ti (Fig. S3†). These results show that metallic Ti atoms react with In-O compounds of mother substrate and the In-O compounds diffuse into Ti metal layer. Unlike conventional adhesive interface that forms the inter-diffusion layer, the roughness of mother substrate can be transferred to the metal surface without leaving residues on both sides due to the stress caused by the plating layer formed on the top.

The transfer of roughness from the mother substrate to metal film was examined with the various type of substrate. $\mathrm{AFM}$ and 3D-profiler were employed to measure the surface roughness of flexible metal film (Fig. 4a) and mother substrates (Fig. 4b). Several kinds of substrates such as ITO glass, fluorinedoped tin oxide (FTO) glass, and STS430 steel, were used as a mother substrate, and invar, $\mathrm{Ti}$ and $\mathrm{Cu}$ were used as the flexible metal film to clarify the relationship between the surface roughness of flexible metal films and that of mother substrate. Si wafer $\left(R_{\mathrm{a}}=0.7 \mathrm{~nm}\right)$, glass $\left(R_{\mathrm{a}}=1.3 \mathrm{~nm}\right)$ and ITOcoated glass $\left(R_{\mathrm{a}}=2.1 \mathrm{~nm}\right)$ were smoother than conventional steel substrates such as rolled STS $430\left(R_{\mathrm{a}}=53.0 \mathrm{~nm}\right.$; mechanically polished) and $\operatorname{STS} 430\left(R_{\mathrm{a}}=129.9 \mathrm{~nm}\right)$. The surface roughness of metal films depends on the roughness of mother substrate. That is, roughness was measured in sequence Ag@Si < invar@glass < Ti/Ni@ITO < Cu@FTO < Cu@rolled STS430 < invar@STS304 (Table 1), and the roughness was evaluated within $2 \%$ from their mother substrates (Fig. $4 \mathrm{c}$ and d).

This result indicates that the roughness of mother substrate was exactly transferred to the detached surface of the flexible metal films. This is the first result that EF metal films with $R_{\mathrm{a}}<1 \mathrm{~nm}$ could be obtained using this surface roughness transfer method without any polishing or planarization process.

In order to evaluate the effects of surface roughness on the performance of optoelectronic devices, top-emitting organic light-emitting diodes (OLEDs; CBP : $\operatorname{Irppy}_{3}, \lambda=510 \mathrm{~nm}$ ) were fabricated on various substrates with different surface roughness, such as glass $\left(R_{\mathrm{a}}=1.3 \mathrm{~nm}\right), \mathrm{EF} \mathrm{Cu}\left(R_{\mathrm{a}}=1.4 \mathrm{~nm}\right)$ and rolled ST340 $\left(R_{\mathrm{a}}=53.0 \mathrm{~nm}\right)($ Fig. $5 \mathrm{a}-\mathrm{c})$. The current density-operating voltage $\left(J-V_{\mathrm{OP}}\right)$ characteristics of OLEDs showed that the device on glass and $\mathrm{EF} \mathrm{Cu}$ had very similar current density $(J=25 \mathrm{~mA}$ $\mathrm{cm}^{-2}$ ) at $V_{\mathrm{OP}} \approx 7.5 \mathrm{~V}$; neither device showed leakage current (Fig. 5d). In contrast, the OLED fabricated on the rolled STS 430 substrate did not work due to leakage current, originated from a high surface roughness $\left(R_{\mathrm{a}}=53 \mathrm{~nm}, R_{\mathrm{t}}=1.9 \mu \mathrm{m}\right)$. The OLED on $\mathrm{EF} \mathrm{Cu}$ had generally higher luminance $L$ at a given $J$ than that on glass (Fig. 5e). At $J=25 \mathrm{~mA} \mathrm{~cm}$ c $^{-2}$, the OLED with $\mathrm{EF} \mathrm{Cu}$
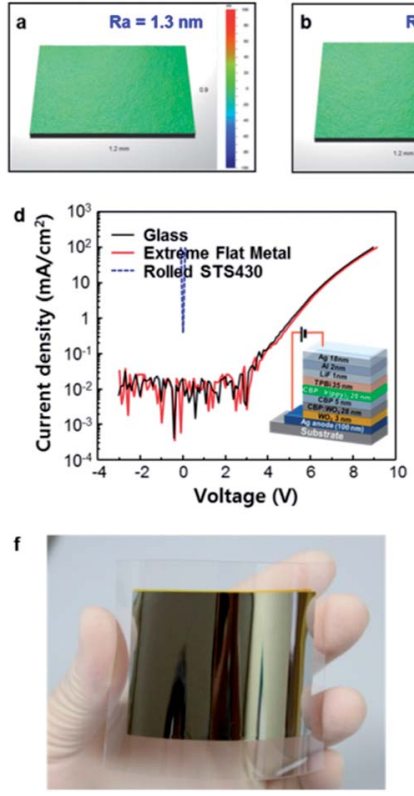

Fig. 5 OLEDs' characteristics with surface roughness. (a) Surface roughness of glass $\left(R_{\mathrm{a}}=1.3 \mathrm{~nm}\right)$, (b) EF Cu $\left(R_{\mathrm{a}}=1.4 \mathrm{~nm}\right)$, and (c) rolled STS430 $\left(R_{\mathrm{a}}=53.0 \mathrm{~nm}\right)$ using a 3D profiler. The measured substrate area was $1.2 \mathrm{~mm} \times 0.9 \mathrm{~mm}$. (d) Current density-voltage and (e) luminance-current density characteristics of OLEDs according to the type of substrate. (f) Optical image of a 3.6-inch EF metal film was fabricated by the surface roughness transfer technology. (g) The 3.6inch OLEDs with the EF Cu substrate (Movie S1†). 
substrate had $L=17100 \mathrm{~cd} \mathrm{~m}^{-2}$, whereas the device on glass had $L=15142 \mathrm{~cd} \mathrm{~m}^{-2}$. This could be due to the better heat dissipation from the OLED on EF Cu substrate than that on glass one (Fig. S4†). To confirm the applicability of the surface roughness transfer method to large area substrate, OLEDs were fabricated on a 3.6-inch EF Cu substrate $\left(R_{\mathrm{a}}=2 \mathrm{~nm}\right)$ (Fig. $\left.5 \mathrm{f}\right)$. All devices emitted light without defective cells when bent in $\mathrm{N}_{2}$ filled glove box (Fig. 5g). Also, the EF $\mathrm{Cu}$ was evaluated as a flexible substrate in organic photovoltaics (OPVs). It was found that electrical properties of OPVs on EF Cu substrate were comparable to those on glass one (Fig. S5†).

\section{Conclusions}

In summary, we fabricated large-area EF metal films by peeling-off the metal film from the mother substrate. To compare peeling-off behaviors depending on the type of metal, surface components of non-reactive $\mathrm{Ag}$ and reactive $\mathrm{Ti}$ were analyzed after they were peeled-off from ITO mother substrate. The interfacial reaction, investigated by in situ synchrotron XPS, evidenced that diffusion of the substrate components at the Ti/ITO interface rather than the $\mathrm{Ag} / \mathrm{ITO}$ interface and the different peeling-off behaviors between them. Despite variations in the materials and methods of forming the metal film, the detached metal film had surface roughness that was within $2 \%$ of that of the mother substrate. Because the EF metal film from roughness transfer method has low surface roughness, excellent thermal conductivity and thermal stability, flexible OLEDs and OPVs fabricated on EF metal films showed superior performance compared to devices fabricated on rigid glass substrates. The novel peel-off approach to fabricate EF film without any additional process, so it would be very useful for mass production of flexible, low-cost, high-throughput and highsmoothness substrate for flexible electronic devices.

\section{Conflicts of interest}

There are no conflicts to declare.

\section{Acknowledgements}

This research was financially supported in part by the National Research Foundation (NRF) of Korea grant funded by the Korea government (MEST) (No. NRF-2013R1A2A2A01069237). The authors also would like to acknowledge support from POSCO.

\section{Notes and references}

1 M. Kaltenbrunner, T. Sekitani, J. Reeder, T. Yokota, K. Kuribara, T. Tokuhara, M. Drack, R. Schwödiauer, I. Graz and S. Bauer-Gogonea, Nature, 2013, 499, 458.

2 M. S. White, M. Kaltenbrunner, E. D. Głowacki, K. Gutnichenko, G. Kettlgruber, I. Graz, S. Aazou, C. Ulbricht, D. A. Egbe and M. C. Miron, Nat. Photonics, 2013, 7, 811.

3 J. Ham and J. L. Lee, Adv. Energy Mater., 2014, 4, 1400539.

4 C.-W. Cheng, K.-T. Shiu, N. Li, S.-J. Han, L. Shi and D. K. Sadana, Nat. Commun., 2013, 4, 1577.
5 X. Yu, T. J. Marks and A. Facchetti, Nat. Mater., 2016, 15, 383. 6 D. Akinwande, N. Petrone and J. Hone, Nat. Commun., 2014, 5, 5678.

7 Y. Li, L. Meng, Y. M. Yang, G. Xu, Z. Hong, Q. Chen, J. You, G. Li, Y. Yang and Y. Li, Nat. Commun., 2016, 7, 10214.

8 D. Liu and T. L. Kelly, Nat. Photonics, 2014, 8, 133.

9 K. I. Park, J. H. Son, G. T. Hwang, C. K. Jeong, J. Ryu, M. Koo, I. Choi, S. H. Lee, M. Byun, Z. L. Wang and K. J. Lee, Adv. Mater., 2014, 26, 2514.

10 X. Pu, L. Li, H. Song, C. Du, Z. Zhao, C. Jiang, G. Cao, W. Hu and Z. L. Wang, Adv. Mater., 2015, 27, 2472.

11 R. He, T. D. Day, J. R. Sparks, N. F. Sullivan and J. V. Badding, Adv. Mater., 2016, 28, 5939.

12 J. Ham, W. J. Dong, J. Y. Park, C. J. Yoo, I. Lee and J. L. Lee, Adv. Mater., 2015, 27, 4027.

13 Y. H. Hwang, J.-S. Seo, J. M. Yun, H. Park, S. Yang, S.-H. K. Park and B.-S. Bae, NPG Asia Mater., 2013, 5, e45.

14 J.-S. Park, T.-W. Kim, D. Stryakhilev, J.-S. Lee, S.-G. An, Y.-S. Pyo, D.-B. Lee, Y. G. Mo, D.-U. Jin and H. K. Chung, Appl. Phys. Lett., 2009, 95, 013503.

15 Y. Fujisaki, H. Koga, Y. Nakajima, M. Nakata, H. Tsuji, T. Yamamoto, T. Kurita, M. Nogi and N. Shimidzu, Adv. Funct. Mater., 2014, 24, 1657.

16 K. Kim, S. Y. Kim and J.-L. Lee, J. Mater. Chem. C, 2014, 2, 2144.

17 S. Kim, J. H. Son, S. H. Lee, B. K. You, K. I. Park, H. K. Lee, M. Byun and K. J. Lee, Adv. Mater., 2014, 26, 7480.

18 (a) C. H. Lee, S. J. Kim, Y. Oh, M. Y. Kim, Y.-J. Yoon and H.-S. Lee, J. Appl. Phys., 2010, 108, 102814; (b) A. Fedorov, R. Van Tijum, W. Vellinga and J. T. M. De Hosson, J. Appl. Phys., 2007, 101, 043520.

19 I.-H. Song, S.-H. Kang, W.-J. Nam and M.-K. Han, IEEE Electron Device Lett., 2003, 24, 580.

20 D. Gupta, M. M. Wienk and R. A. Janssen, Adv. Energy Mater., 2013, 3, 782.

21 J.-M. Delgado-Sanchez, N. Guilera, L. Francesch, M. D. Alba, L. Lopez and E. Sanchez, ACS Appl. Mater. Interfaces, 2014, 6, 18543.

22 R. Kapadia, Z. Yu, H.-H. H. Wang, M. Zheng, C. Battaglia, M. Hettick, D. Kiriya, K. Takei, P. Lobaccaro and J. W. Beeman, Sci. Rep., 2013, 3, 2275.

23 X. Hu, Z. Song, W. Liu, F. Qin, Z. Zhang and H. Wang, Appl. Surf. Sci., 2012, 258, 5798.

24 X. Liu, Y. Liu, Y. Liang, H. Liu, Z. Zhao and B. Gao, Thin Solid Films, 2011, 520, 400.

25 W. Wang, M. Song, T. S. Bae, Y. H. Park, Y. C. Kang, S. G. Lee, S. Y. Kim, D. H. Kim, S. Lee and G. Min, Adv. Funct. Mater., 2014, 24, 1551.

26 D. J. Yun, S. H. Lim, T. W. Lee and S. W. Rhee, Org. Electron., 2009, 10, 970.

27 S. H. Kim, J. H. Cheon, E. B. Kim, J. H. Bae, J. H. Hur and J. Jang, J. Non-Cryst. Solids, 2008, 354, 2529.

28 H. Won Choi, S. Young Kim, K.-B. Kim, Y.-H. Tak and J.-L. Lee, Appl. Phys. Lett., 2005, 86, 012104.

29 D. Barin, Thermochemical Data of Pure Substances, WileyVCH, 1997. 
30 H. Lee, H. W. Jang, K.-B. Kim, Y.-H. Tak and J.-L. Lee, J. Appl. Phys., 2004, 95, 586.

31 W. J. Dong, J. Y. Park, J. Ham, G. H. Jung, I. Lee and J. L. Lee, Adv. Funct. Mater., 2016, 26, 5437.
32 W. J. Dong, G. H. Jung and J.-L. Lee, Sol. Energy Mater. Sol. Cells, 2013, 116, 94.

33 L. Nardi, N. Yang, C. F. Dickens, A. L. Strickler and S. F. Bent, Adv. Energy Mater., 2015, 5, 1500412. 